\title{
Influence of Nano-Modification on the Interlaminar Shear Strength of Unidirectional Glass Fiber-Reinforced Epoxy Resin
}

\author{
M. Rajanish, N. V. Nanjundaradhya, Ramesh S. Sharma \\ R \& D Centre, Department of Mechanical Engineering, R.V. College of Engineering, Bangalore, India \\ Email: prof.m.rajanish@gmail.com
}

Received 7 May 2014; revised 11 June 2014; accepted 25 June 2014

Copyright (C) 2014 by authors and Scientific Research Publishing Inc. This work is licensed under the Creative Commons Attribution International License (CC BY). http://creativecommons.org/licenses/by/4.0/

(c) (i) Open Access

\begin{abstract}
Interlaminar shear properties of the fibre reinforced polymer composites are very important in many structured applications. It has been reported that interlaminar shear strength (ILSS) of fibre reinforced polymer composites may be improved by the modification of the matrix. In this paper, diglycidyl ether of bisphenol A (DGEBA)/triethylene tetramine (TETA) system is used as the starting epoxy matrix. Alumina nanoparticles are employed to modify the epoxy matrix at various concentrations. Unmodified and modified epoxy resins are used along with unidirectional glass fibres for fabricating composite laminates by vaccum bagging method. The interlaminar shear strength of the glass fibre reinforced composites is investigated and the results indicate that introduction of the alumina nanoparticles enhances the ILSS. In particular, the addition of $0.8 \mathrm{wt} \%$ alumina nanoparticles leads to maximum enhancement in the ILSS; however, there is a decrease in the value with further addition. The dispersion of alumina nanoparticles and the fracture surfaces of the fibre reinforced composites are examined by the scanning electron microscope. The graphs are employed to explain the results.
\end{abstract}

\section{Keywords}

Nanomodifications, ILSS, Glass Fibre, Epoxy, FRP

\section{Introduction}

Fiber reinforced composite materials are demanded by the industry because of their high specific stiffness/

How to cite this paper: Rajanish, M., Nanjundaradhya, N.V. and Sharma, R.S. (2014) Influence of Nano-Modification on the Interlaminar Shear Strength of Unidirectional Glass Fiber-Reinforced Epoxy Resin. Journal of Minerals and Materials Characterization and Engineering, 2, 264-269. http://dx.doi.org/10.4236/immce.2014.24031 
strength, especially for applications where weight reduction is critical [1] [2]. By using composites, weight of a structure can be reduced significantly. ILSS strength of the composite is usually a limiting design. Thus, the enhancement of ILSS of a composite is of high importance. It has been reported that it is possible to enhance the ILSS of a fiber reinforced composite via matrix modification by the introduction of the nanoparticles [3]. Nanoparticles are presently considered to be high potential filler materials for the improvement of the mechanical and physical properties. The nanometric size, leading to the huge specific surface areas (SSA) of up to more than $1000 \mathrm{~m}^{2} / \mathrm{g}$, and their unique properties have caused intensive research activities in the field of natural and engineering sciences [4]. Their mechanical properties with electrical and thermal properties make them interesting materials for the use as fillers in polymers and open up new perspectives for multi-functional materials. An efficient exploitation of the properties of the nanoparticales in order to improve the material performance generally related to the degree of dispersion, impregnation with matrix and to the interfacial adhesion [5]. The advantage of the nano scaled particles compared to the micro scaled fillers is their enormous surface area, which can act as interface for stress-transfer. However, a high SSA causes the formation of agglomerates. The agglomerates of the nanocomposite are difficult to separate and to infiltrate with the matrix. Hence an efficient technique has to be employed to disperse nanoparticales in epoxy resins showing better dispersibility [6]. The ultrasonication is found to be one of the best methods to disperse the nanoparticles in the epoxy resin matrix. Thus in this work, the alumina nanoparticles are dispersed in the epoxy by the ultrasonication technique and the influences over the ILSS properties of glass fiber reinforced modified epoxy resin are studied.

\section{Experimental}

\subsection{Materials}

Epoxy resin supplied by Ciba-Geigy India Ltd, is a two part system, base resin; diglycidyl ether of bisphenol A (DGEBA) and hardener; triethylene tetramine. The two parts were mixed together in a ratio of 10:1 by weight. The epoxy resin was modified using alumina nanoparticles supplied by M/S Nanobeach, India. The average particle size of the nanoparticles is $20 \mathrm{~nm}$. The modified epoxy was then reinforced with glass fibre to form composites. The glass fabric used was a unidirectional sheet of 220 gsm (Style; 92145) purchased from P-D Interglas Technologies, Erbach.

\subsection{Preparation of Composites}

The base resin in the stoichiometric amount was used as the starting matrix and it was modified by the alumina nanoparticles. Alumina nanoparticles in different proportions (0.2 wt $\%, 0.4 \mathrm{wt} \%, 0.6 \mathrm{wt} \%, 0.8 \mathrm{wt} \%, 1.0 \mathrm{wt} \%$ and $1.2 \mathrm{wt} \%$ ) were added slowly to resin and then mechanical stirring was done for about 30 minutes. After the mechanical stirring, modified epoxy solution was subjected to the ultrasonification for about 30 minutes. Sonification is done to speed dissolution, by breaking intermolecular interactions of the nano particle and intercalation of monomer into interlayer galleries. The solution was mixed with the hardener and stirring up to 5 - 10 min was repeated.

The laminates were prepared by vaccum bagging technique and were cured by leaving them at the room temperature for 24 hours. To generate the base line data, glass fibre reinforced epoxy lamina without nanoparticles were also prepared. Care was taken that all the material system was processed under same condition using the same sequence of operations. The specimens for the test were machined from the laminates to the following dimensions: Length: $48 \mathrm{~mm}$, width: $16 \mathrm{~mm}$, thickness: $8 \mathrm{~mm}$. All the samples prepared were of the same dimensions with the $48 \%$ fibre by weight.

\subsection{Measurements}

Following the ASTM D-2344 standard, the short beam shear (three point bending) test was conducted on a Biss universal testing machine under $25 \mathrm{KN}$ load cell with a cross head speed of about $1 \mathrm{~mm} / \mathrm{min}$. Span to thickness ratio was 4 . The apparent interlaminar shear strength (ILSS) was calculated from the classical beam relationship:

$$
\tau=3 P / 4 b h
$$

where, " $\tau$ " is the maximum interlaminar shear strength at the failure, " $P$ " is the maximum load, " $b$ " is the specimen width and " $h$ " is the specimen thickness. 


\section{Results and Discussions}

Mainly two different types of the composite laminates were fabricated based on matrices: a) unmodified epoxy/ glass fibre reinforced composites b) Alumina filled epoxy/glass fibre composite with the different filler concentrations such as $0.2 \mathrm{wt} \%, 0.4 \mathrm{wt} \%, 0.6 \mathrm{wt} \%, 0.8 \mathrm{wt} \%, 1.0 \mathrm{wt} \%$ and $1.2 \mathrm{wt} \%$. Thus the ILSS test is conducted for all the specimens. Figure 1 shows the loading of the specimen for the test. The results for the interlaminar shear strength obtained from the tests are shown in the Figure 2. It exhibits that the ILSS of the modified epoxy/glass fibre composite is higher than that of the unmodified epoxy/glass fibre composite. The percentage enhancement of ILSS is shown in the Figure 3. For the modified epoxy/glass fibre composite, the use of the alumina nano particles is found to improve the ILSS with the maximum enhancement of the $2.07 \%$ in the direction of fibres (0 degree) for $0.8 \mathrm{wt} \%$. Further addition of the nanoparticles up to $1.2 \mathrm{wt} \%$ decreases the interlaminar shear strength of the composite.

The modification of the epoxy matrix by the alumina nano particles is effective in improving load transfer between glass fibre and epoxy matrix since nano particles can form bridging between fibres and matrix. Figure 4 shows the SEM image of the fractured surface of the specimen with lower magnification. The alumina filled epoxy along with the fibres may be observed in the image. At low concentration, alumina particle exhibits uniform dispersion in epoxy, while at higher concentration agglomeration is depicted.

Figures 5-7 show SEM images of the specimens with $0.6 \mathrm{wt} \%, 0.8 \mathrm{wt} \%$ and $1.0 \mathrm{wt} \%$ alumina in the epoxy. The agglomeration of nanoparticles may be observed in the specimen with $1.0 \mathrm{wt} \%$ alumina as compared 0.6 wt $\%, 0.8$ wt\% alumina in epoxy. The agglomerated nanoparticles cause negative effect on the ILSS property of the composite because of the poor bonding. The improved dispersion of the alumina nanoparticles in epoxy resin results in improved ILSS of alumina nanoparticles filled epoxy/glass fiber nanocomposite as compared to neat epoxy/glass fiber composite and also composite with agglomeration of nanoparticles in epoxy.

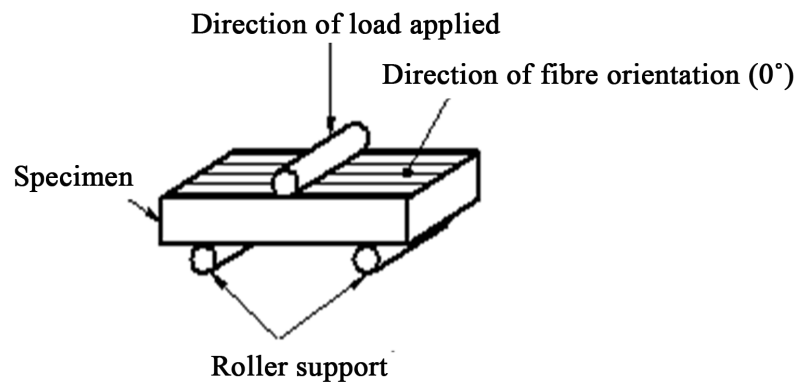

Figure 1. Loading of specimen for ILSS test.

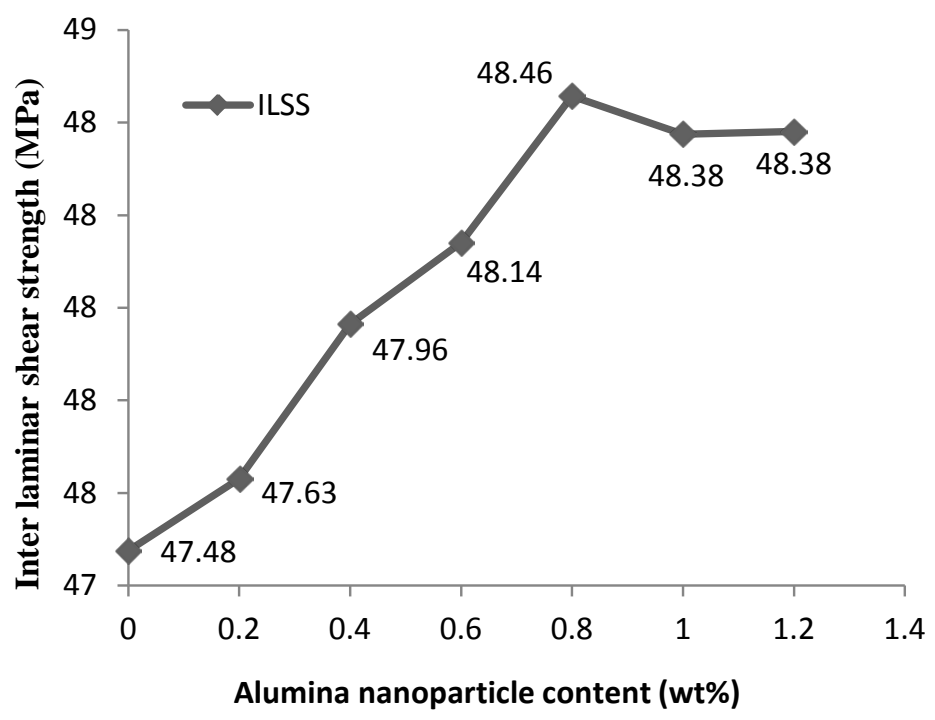

Figure 2. Interlaminar shear strength of the composite laminates. 


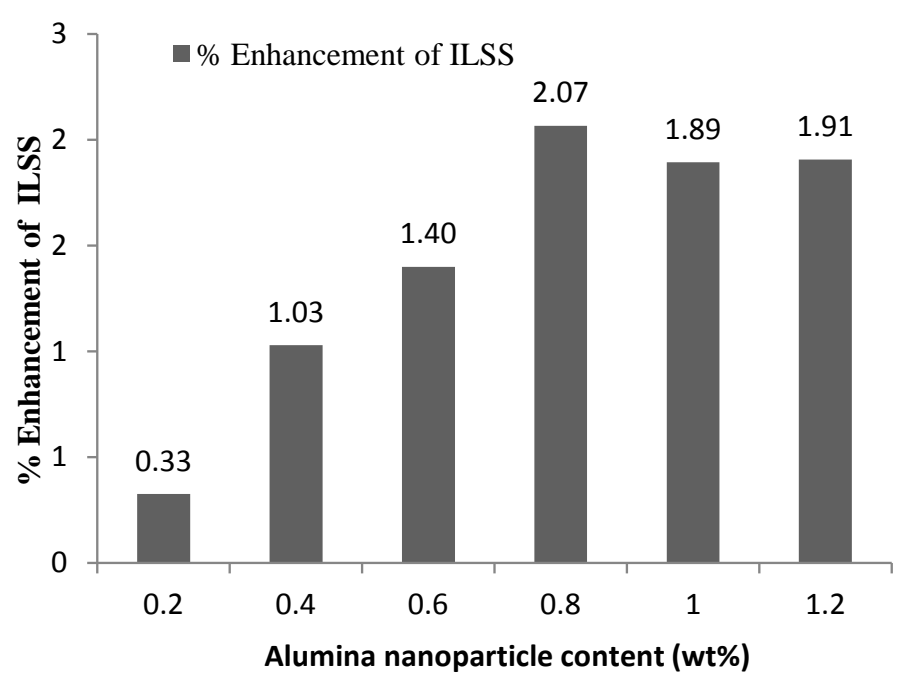

Figure 3. Enhancement of ILSS in the composite laminate for different filler content.

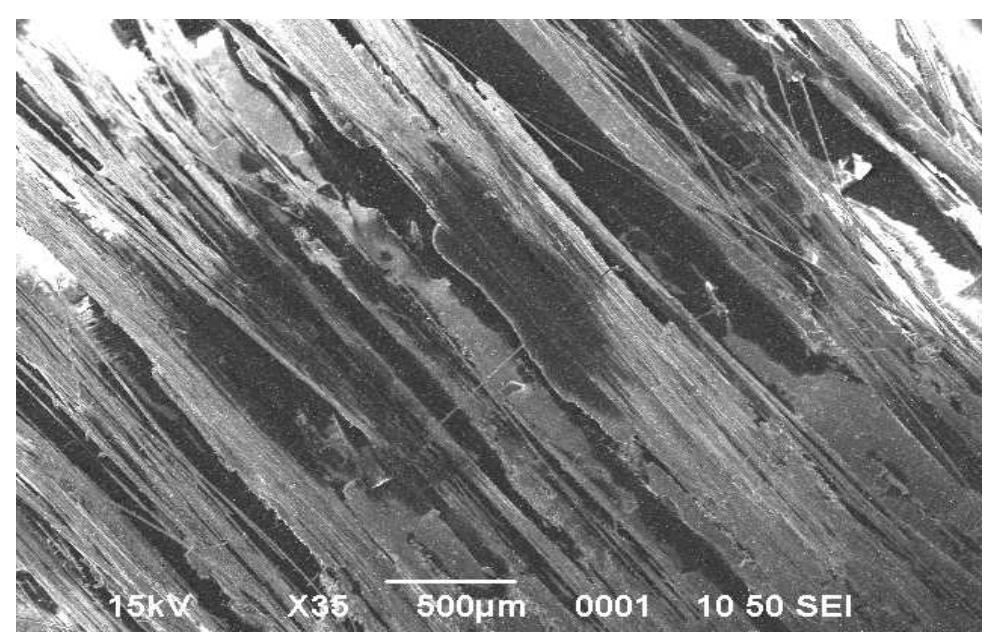

Figure 4. SEM image of the fractured surface of the specimen.

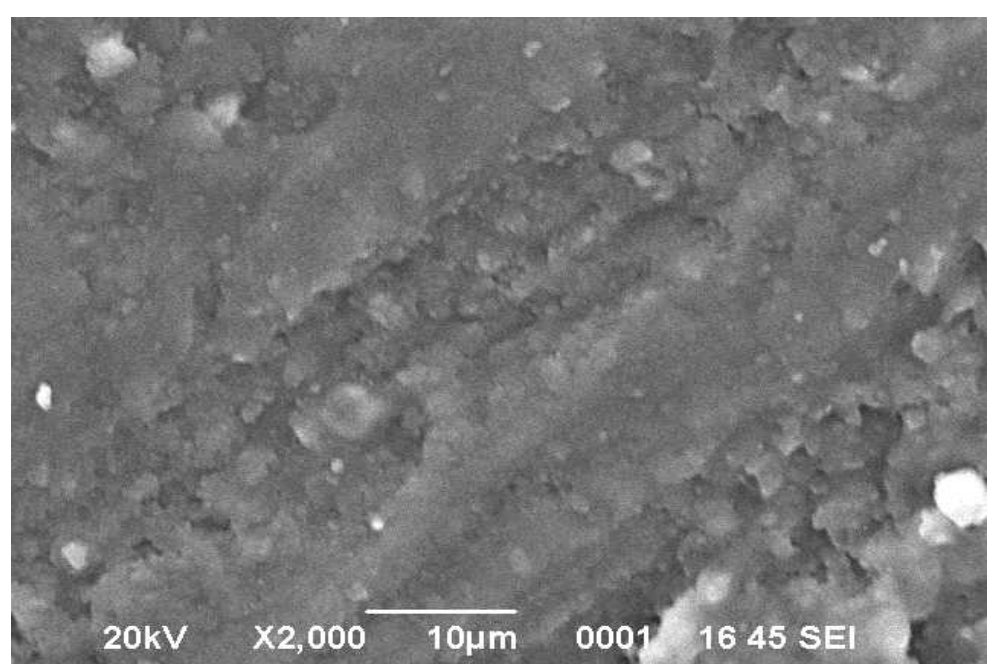

Figure 5. SEM image of the specimens with $0.6 \mathrm{wt} \%$ alumina in the epoxy. 


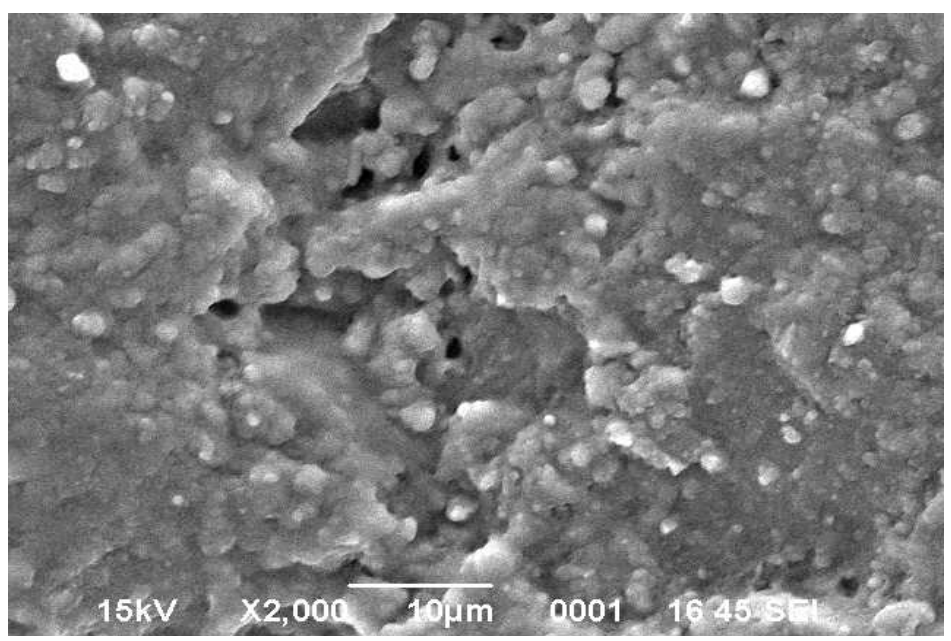

Figure 6. SEM image of the specimen with $0.8 \mathrm{wt} \%$ alumina in the epoxy.

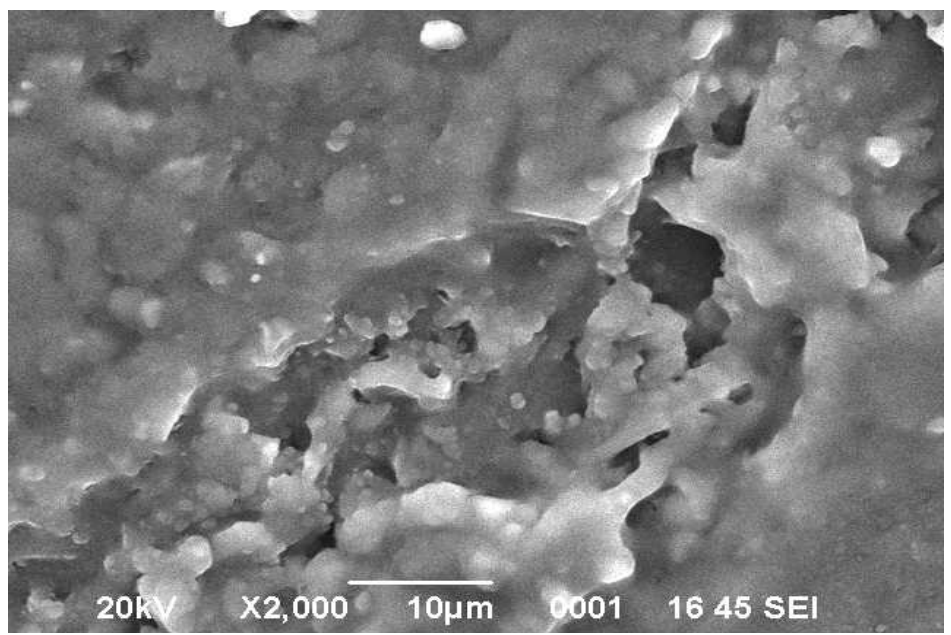

Figure 7. SEM image of the specimen with $1.0 \mathrm{wt} \%$ alumina in the epoxy.

\section{Conclusion}

In this paper, an experimental study on the interlaminar shear strength of alumina nanoparticles filled epoxy/ glass fiber composite is presented. The result indicates that the loadings of alumina nanoparticles improve the ILSS of the epoxy based composite. At low concentration, alumina particle exhibits uniform dispersion in epoxy, while at higher concentration agglomeration is depicted. The improved dispersion of the alumina nanoparticles in epoxy resin results in improved ILSS of alumina nanoparticles filled epoxy/glass fiber nanocomposite as compared to neat epoxy/glass fiber composite.

\section{Acknowledgements}

Authors thankfully acknowledge the Management, Principal and Head of the Department, Mechanical Engineering, R.V. College of Engineering, Bangalore and also Department of Mechanical Engineering, Dayananda Sagar Academy of Technology and Management, Bangalore-India, for the support \& encouragement received to carry out this work.

\section{References}

[1] (2008) Grit, the Advantages of Epoxy Resin versus Polyester in Marine Composite Structure. RINA Marine Renewable Energy Conference, The Royal Institution of Naval Architects. 
[2] Whitney, J.M. and Browning, C.E. (1985) On Short-Beam Shear Tests for Composite Materials. Experimental Mechanics, 25, 294-300. http://dx.doi.org/10.1007/BF02325100

[3] Liu, Y., Feng, Q.-P. and Fu, S.-Y. (2012) Role of Matrix Modification on Interlaminar Shear Strength of Glass Fibre/ Epoxy Composites. Composites Part B: Engineering, 43, 95-98. http://dx.doi.org/10.1016/j.compositesb.2011.04.037

[4] Koo, J.H. (2006) Polymer Nanocomposite, Processing, Characterization and Application. McGraw-Hill Companies, USA.

[5] Ragosta, G. (2005) Epoxy-Silica Particulate Nanocomposite: Chemical Interactions, Reinforcement and Fracture Toughness. Polymer, 46, 10506-10516. http://dx.doi.org/10.1016/j.polymer.2005.08.028

[6] Kurimoto, M., et al. (2007) Improvement of Dispersibility of Nano Fillers in Epoxy/Alumina Nanocomposite by Application of Ultrasonic Wave. Proceedings of International Symposium on Eco Topia Science, ISETS07. 
Scientific Research Publishing (SCIRP) is one of the largest Open Access journal publishers. It is currently publishing more than 200 open access, online, peer-reviewed journals covering a wide range of academic disciplines. SCIRP serves the worldwide academic communities and contributes to the progress and application of science with its publication.

Other selected journals from SCIRP are listed as below. Submit your manuscript to us via either submit@scirp.org or Online Submission Portal.
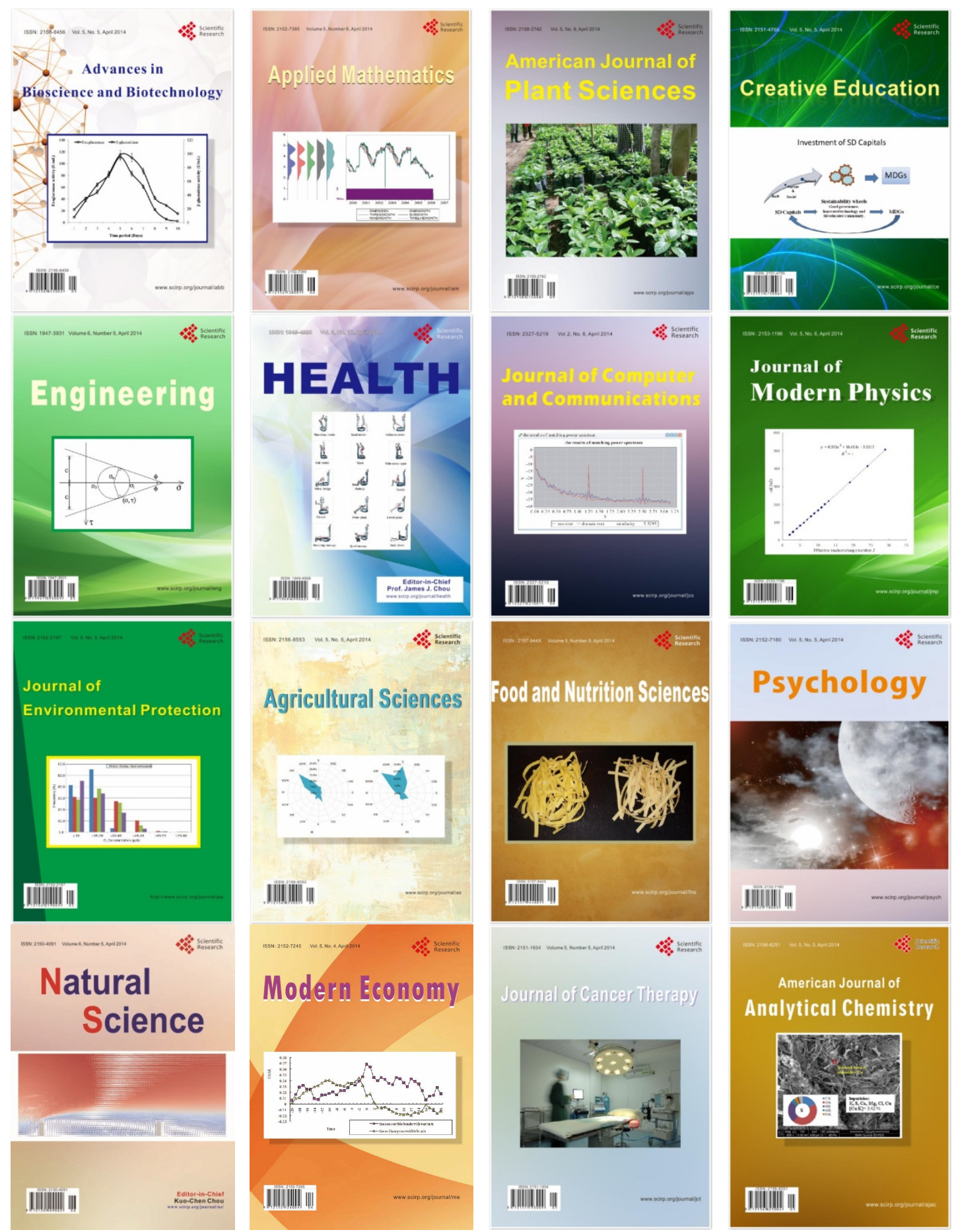